\title{
Minimally Invasive CABG or Hybrid Coronary Revascularization for Multivessel Coronary Diseases: Which Is Best? A Systematic Review and Metaanalysis
}

\author{
Zhiyuan Guan, PHD, Zhe Zhang, MD, Kaiyun Gu, PHD, Heqing Wang, PHD, Jin Lin, MD, \\ Wenjun Zhou, MD, Feng Wan, PHD \\ Department of Cardiology surgery, Peking University Third Hospital, Haidian District, Beijing, China
}

\section{ABSTRACT}

Objectives: Minimally invasive coronary revascularization (MICR) involves minimally invasive direct coronary artery bypass grafting (MIDCAB) and robotic-assisted coronary artery bypass grafting (RCABG), and hybrid coronary revascularization (HCR) aims to combine MICR/RCABG on left anterior descending (LAD) and percutaneous coronary interventions (PCI) on non-LAD lesions. We performed a systematic review and metaanalysis to compare clinical outcome after MICR and HCR.

Methods: A metaanalysis was carried out through searching PubMed, EMBASE, Web of Science, and Medline for comparative studies evaluating the primary and secondary clinical end points.

Results: A systematic literature search identified 8 observational studies that satisfied our inclusion criteria, including being suitable for metaanalysis; the studies were between 1990 and 2018 and included 1084 cases of HCR and 2349 cases of MICR. Metaanalysis of these studies showed that HCR was associated with a reduced need for ICU LOS (WMD -11.46 hours, $95 \%$ CI, $-18.76 \sim-4.25, P$ $=.02)$, to hospital time (WMD -1.34 hours, $95 \%$ CI, -2.42 to $0.26, P<.01$ ), and blood transfusion (OR $0.43,95 \% \mathrm{CI}$, $0.31-0.59, P<.00001)$ than MICR. Comparisons of individual components showed no significant difference in terms of in-hospital mortality, MACCE, shock, myocardial

Received April 9, 2019; received in revised form September 2, 2019; accepted September 12, 2019.

Abbreviations: AKI, acute kidney disease; BITA, bilateral internal mammary artery grafts; $C A B G$, coronary artery bypass grafting; $C K D$, chronic kidney disease; $C P B$, cardiopulmonary bypass; HCR, bybrid coronary revascularization; ICU LOS, length of stay in an intensive care unit; MICR, minimally invasive coronary revascularization; $L A D$, left anterior descending; $L C X$, circumflex branch; MACCE, major adverse cerebrovascular events; MI, myocardial infarction; MIDCAB, minimally invasive direct coronary artery bypass grafting; PCI, percutaneous coronary interventions; RCABG, robotic-assisted coronary artery bypass grafting; WMD, weighted mean difference

Correspondence: Zhe Zhang, 49 North Garden Rd., Haidian District, Beijing 100191, China; (e-mail: Zhangzhe@bjmu.edu.cn). infarction (MI), long-term survival, total variable cost, and surgical complications (including renal failure, chest drainage, bleeding).

Conclusions: HCR was noninferior to MICR in terms of in-hospital mortality, MACCE, shock, MI, long-term survival, total variable cost, and surgical complications (including renal failure, chest drainage, bleeding), whereas HCR was associated with a reduced need for ICU LOS, hospital time, and blood transfusion than MICR and less infection than MICR. Further randomized studies are warranted to corroborate these observational data.

\section{INTRODUCITON}

Coronary artery bypass grafting (CABG) was first introduced in the 1960s [Kolessov 1967]; the application of CABG in coronary disease has expanded to include minimally invasive coronary revascularization (MICR) and hybrid coronary revascularization (HCR) [Barsoum 2015]. MICR involves minimally invasive direct coronary artery

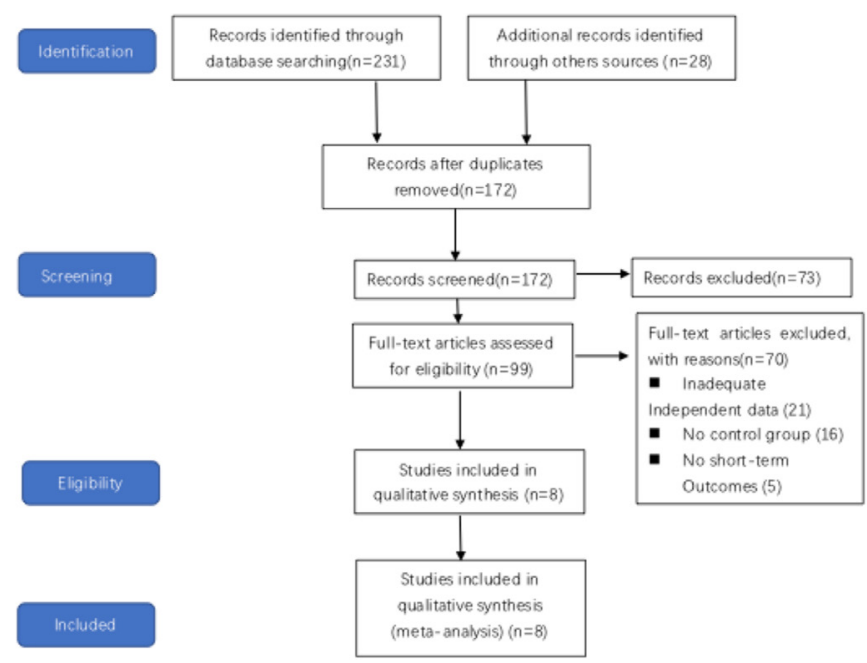

Figure 1. Search strategy. 
Table 1. Quality Analysis of 8 Studies

\begin{tabular}{|c|c|c|c|c|c|c|c|c|}
\hline Group A* & 1 & 1 & 1 & 1 & 1 & 1 & 1 & 1 \\
\hline Group B† & 1 & 1 & 1 & 0 & 1 & 0 & 1 & 1 \\
\hline \multicolumn{9}{|l|}{ Comparability } \\
\hline Group D§ & 5 & 5 & 5 & 3 & 5 & 3 & 4 & 4 \\
\hline Group E\|l & 5 & 4 & 4 & 5 & 4 & 5 & 4 & 4 \\
\hline \multicolumn{9}{|l|}{ Outcome } \\
\hline Group FI & 1 & 1 & 1 & 1 & 1 & 1 & 1 & 1 \\
\hline
\end{tabular}

*Group A. Assignment for treatment-any criteria reported? (If yes, score of 1). $<<$ We have changed to "score of 1 here and throughout the table; is that what you mean?>>

†Group B. How representative was the reference group (MICR) in comparison to the general population for CABG? (If yes, score of 1; no score if the patients were selected or selection of group was not described). 《<Clarify this part in response to the question you raise. $>$

$\ddagger$ Group C. How representative was the treatment group (HCR) in comparison to the general population for CABG? (If drawn from the same community as the reference group, score of 1; no score if drawn from a different source or selection of group was not described.)

§Group D. Groups comparable for 1, 2, 3, 4, 5 . (If yes, score of 1 was assigned for each of these. No star was assigned if the 2 groups differed.) Comparability variables: (1) age; (2) sex; (3) hypertension; (4) diabetes; (5) ejection fraction; (6) 3-vessel disease; (7) left main stem disease; (8) urgent/emergency operation; (9) viability studies; (10) surgeon or hospital volume.

"Group E. Groups comparable for 6, 7, 8, 9, 10. (If yes, 1 star was assigned for each of these. No star was assigned if the 2 groups differed.) Comparability variables: (1) age; (2) sex; (3) hypertension; (4) diabetes; (5) ejection fraction; (6) 3-vessel disease; (7) left main stem disease; (8) urgent/emergency operation; (9) viability studies; (10) surgeon or hospital volume.

IGroup F. Outcome assessment: clearly defined outcome of interest (if yes, 1 star).

\#Group G. Outcome assessment: follow-up (score of 1 if described.)

bypass grafting (MIDCAB) and robotic-assisted coronary artery bypass grafting (RCABG). MICR procedures have aimed to further reduce invasiveness through a small incision without cardiopulmonary bypass, and MICR also shows better clinic outcome with fewer complication in terms of bleeding, draining, mediastinitis, and long-term survival [Sim 1999; Thiele 2009; Ruel 2014; Soylu 2016], has lower costs [Ruel 2013], and shows excellent graft patency for patients with multivessel revascularization [Aziz 2007]. HCR aims to combine MICR/RCABG on left anterior descending (LAD) and percutaneous coronary interventions (PCI) on non-LAD lesions, which is the most proven efficacious therapeutic proposal of cardiac surgery and interventional cardiology and has also increasingly been used to treat multivessel coronary artery disease [Aziz 2007; Puskas 2016]; and HCR aims to reduce recovery duration, hospital complications, and surgery trauma [Harskamp 2014; Phan 2015]. However, there is a lack of robust clinical evidence and available data to evaluate the effectiveness of HCR and MICR with multivessel coronary disease. With the aim of filling this knowledge gap, we compared the main clinical outcomes in patients by using HCR and MICR and analyzed which surgery techniques were better in patients with multivessel coronary disease.

\section{METHODS}

\section{Search Strategy and Definition}

Our strategy was to use a comprehensive search of PubMed, EMBASE, Web of Science, and Medline from January 1990 to January 2018 with MESH search headings, "minimally invasive coronary revascularization," "hybrid coronary revascularization," "minimally invasive direct coronary artery bypass grafting," "robotic-assisted coronary artery bypass grafting," "multivessel coronary disease," "integrated myocardial revascularization." We define 30-days mortality and major adverse cerebrovascular events (MACCE [composite of all-cause mortality, myocardial infarction, and stroke]) as the primary clinical end points and regard reoperation rate, chest drainage, operation time, bleeding, length of stay in an intensive care unit (ICU LOS), hospital time, revascularization, blood transfusion, infection and ventilation times, total variable cost into shock, MI, renal failure, and long-term follow-up of survival as secondary clinical end points. 
Table 2. The Baseline of Patients' Characteristics

\begin{tabular}{|c|c|c|c|c|c|c|c|}
\hline Study & Type & Study period & $\mathrm{HCR}$ & MIDCAB & $\mathrm{HCR}$ & $\begin{array}{l}\text { RCABG/ } \\
\text { MIDCAB }\end{array}$ & Follow-up \\
\hline [Bonatti 2012] & $\mathrm{RCS}$ & 2001 Jun to 2011 Jun & 140 & 64 & $\begin{array}{l}\text { Simultaneous } 28 \mathrm{PCl} \text { before sur- } \\
\text { gery 38; surgery before } \mathrm{PCl} 74\end{array}$ & RCABG 64 & 5 years \\
\hline [Khaliel 2017] & $\mathrm{RCS}$ & 2003 Oct to 2015 Oct & 147 & 336 & Simultaneous & RCABG & 12 years \\
\hline [Repossini 2013] & $\mathrm{RCS}$ & 1997 May to $2011 \mathrm{Feb}$ & 166 & 810 & 2 Stage & MIDCAB & $4.5 \pm 2.3$ years \\
\hline [Rosenblum 2016] & $\mathrm{RCS}$ & 2003 Oct to $2013 \mathrm{Dec}$ & 306 & 873 & 2 Stage & RCABG & 5 years \\
\hline [Yang 2015] & $\mathrm{RCS}$ & 2007 Feb to 2014 Oct & 100 & 140 & Simultaneous & RCABG & 3 years \\
\hline
\end{tabular}

\section{Eligibility Criteria}

The inclusion of studies was done according to the following: observational studies and randomized controlled trials (RCTs) comparing HCR and MICR in multivessel coronary disease, with at least 10 patients included in each cohort (Figure 1). Animal studies and review papers were excluded. Studies that did not have any of the desired outcome measures or had participants who were treated by other modalities such as percutaneous coronary intervention and emergency or salvage conditions were excluded. Studies with incomplete data were excluded.

\section{Data Extraction and Critical Appraisal}

We reviewed all abstracts, studies, and citations irrespective of the language in which the study was written. Three authors (Z. G., K. G., J. L.) reviewed independently by extracting the following data from each study: first author, year of publication, trial characteristics, study design, inclusion and exclusion criteria, graft type, clinic outcome (Figure 1). The modified Newcastle-Ottawa scale was carried out in our metaanalysis with a quality assessment score. The modified Newcastle-Ottawa scale checklist has been summarized in Table 1, and we also define the studies' scores higher than 7 as indicating high-quality studies Table 1 . The quality of all studies has been evaluated by 2 authors, considered as independent researchers (W. Z., J. L.).

\section{Statistical Analysis}

Group statistics are expressed as mean \pm standard deviation. The odds ratios (ORs) were used as the common measure for dichotomous data. Random effect models are mostly used in studies with large differences, mainly because patients undergoing operations in different centers have varying risk profiles and selection criteria for each surgical technique. All analyses were conducted using Review Manager version 5.3 software for Windows (The Nordic Cochrane Centre, The Version
5.3, Cochrane Collaboration, Copenhagen, Denmark; 2014). We evaluated heterogeneity by focusing on patients with left ventricular dysfunctions and a quality score greater than 7 . We also used a funnel plot to assess publication bias and defined $5 \%$ as the level of significance with a $95 \%$ confidence interval.

\section{RESULTS}

\section{Study Characteristics}

We identified 8 observational studies that satisfied our inclusion criteria, including being suitable for metaanalysis; the studies were between 1990 and 2018 and included 1084 cases of HCR and 2349 cases of MICR. The date extraction was done by 2 authors, and Table 1 presents the baseline characteristics of the metaanalysis. Four studies used a single-stage approach for HCR, and 4 other studies used a staged approach for HCR. Four studies used MICR, and 4 other studies used HCR. Mean age of the patients ranged from 58 to 73 years; the male population varied from $27 \%$ to $84 \%$, whereas duration of follow-up ranged from in-hospital to 10.3 years (Tables 2 and 3).

\section{Outcomes of Metaanalysis}

See Figures 2-5 [Bonatti 2012; Repossini 2013; Halkos 2014; Rosenblum 2015; Yang 2015; Khaliel 2017; Lufeng 2017; Farid 2018].

Primary clinical end point: in-hospital mortality. For in-hospital mortality in HCR $(0.626 \%)$ and MICR $(0.563 \%)$ in 4 studies, the results showed significant difference (OR $0.91 ; 95 \% \mathrm{CI}, 0.22-3.77 ; P=.9)$. However, in subgroup analysis, HCRs are similar to MICRs (OR 0.73; 95\% CI, 0.105.36; $Z=0.31 ; P=.75$ ) and RCABGs (OR 1.18; 95\% CI, $0.42-3.33 ; Z=0.32 ; P=.75)$.

In view of MACCE in HCR (1.59\%) and MICR $(1.69 \%)$ in 4 studies, the results showed that MACCE 
Table 3. The Baseline of Patients' Characteristics

\begin{tabular}{|c|c|c|c|c|c|c|c|c|c|c|c|c|}
\hline \multirow[t]{2}{*}{$\begin{array}{l}\text { [Bonatti } \\
\text { 2012] }\end{array}$} & $\mathrm{HCR}$ & 140 & 61 & $\begin{array}{c}111 \\
(79.3 \%)\end{array}$ & $\begin{array}{c}40 \\
(28.6 \%)\end{array}$ & $\begin{array}{c}118 \\
(84.3 \%)\end{array}$ & $\begin{array}{c}61 \\
(43.6 \%)\end{array}$ & $\begin{array}{c}40 \\
(28.6 \%)\end{array}$ & $\begin{array}{c}16 \\
(11.4 \%)\end{array}$ & $\begin{array}{c}0.60 \\
(0.20-0.79)\end{array}$ & $\begin{array}{c}2 \\
(0-13)\end{array}$ & $\begin{array}{c}29 \\
(19-90)\end{array}$ \\
\hline & $\begin{array}{c}\text { MIDCAB/ } \\
\text { RCABG }\end{array}$ & 64 & 62 & $\begin{array}{c}50 \\
(78.1 \%)\end{array}$ & $\begin{array}{c}19 \\
(29.7 \%)\end{array}$ & $\begin{array}{c}53 \\
(82.8 \%)\end{array}$ & $\begin{array}{c}20 \\
(31.3 \%)\end{array}$ & $\begin{array}{c}22 \\
(34.4 \%)\end{array}$ & $6(9.4 \%)$ & $\begin{array}{c}0.55 \\
(0.30- \\
0.85)\end{array}$ & $\begin{array}{c}2 \\
(0-11)\end{array}$ & $\begin{array}{c}27 \\
(14-40)\end{array}$ \\
\hline \multirow[t]{2}{*}{$\begin{array}{l}\text { [Farid } \\
\text { 2018] }\end{array}$} & $\mathrm{HCR}$ & 82 & $64 \pm 9.82$ & 64 & 86 & NS & NS & NS & 6 & & $\begin{array}{c}2.63 \pm \\
2.90\end{array}$ & NS \\
\hline & $\begin{array}{l}\text { MIDCAB/ } \\
\text { RCABG }\end{array}$ & 100 & $61 \pm 10.1$ & 86 & 13 & NS & NS & NS & 10 & & $\begin{array}{c}2.03 \pm \\
1.92\end{array}$ & NS \\
\hline \multirow[t]{2}{*}{$\begin{array}{l}\text { [Khaliel } \\
\text { 2017] }\end{array}$} & $\mathrm{HCR}$ & 147 & $\begin{array}{c}61.2 \pm \\
11.0\end{array}$ & $113(76.9)$ & 21 & NS & NS & NS & 4.7 & NS & NS & NS \\
\hline & $\begin{array}{c}\text { MIDCAB/ } \\
\text { RCABG }\end{array}$ & 336 & $\begin{array}{c}61.2 \pm \\
10.5\end{array}$ & $\begin{array}{c}250 \\
(74.4)\end{array}$ & 12 & NS & NS & NS & 6.3 & NS & NS & NS \\
\hline \multirow[t]{2}{*}{$\begin{array}{l}\text { [Repossini } \\
\text { 2013] }\end{array}$} & $\mathrm{HCR}$ & 166 & $\begin{array}{c}65.8 \pm \\
10.3\end{array}$ & 150 & 40 & 130 & NS & 45 & 24 & NS & NS & NS \\
\hline & $\begin{array}{l}\text { MIDCAB/ } \\
\text { RCABG }\end{array}$ & 810 & $\begin{array}{c}64.6 \pm \\
12.0\end{array}$ & 0.838 & NS & NS & NS & NS & NS & NS & NS & NS \\
\hline $\begin{array}{l}\text { [Rosen- } \\
\text { blum } \\
2016]\end{array}$ & $\mathrm{HCR}$ & 306 & $\begin{array}{c}64.4 \pm \\
11.9\end{array}$ & 215 & $\begin{array}{c}113 \\
(36.9)\end{array}$ & $\begin{array}{c}280 \\
(91.5)\end{array}$ & NS & $63(20.6)$ & NS & NS & NS & $\begin{array}{c}28.3 \pm \\
5.3\end{array}$ \\
\hline \multirow[t]{2}{*}{$\begin{array}{l}\text { [Zhang } \\
\text { 2017] }\end{array}$} & $\mathrm{HCR}$ & 40 & $\begin{array}{c}65.6 \pm \\
8.4\end{array}$ & 28 & 22 & 11 & 8 & NS & NS & $\begin{array}{c}66.95 \pm \\
7.14\end{array}$ & NS & NS \\
\hline & $\begin{array}{l}\text { MIDCAB/ } \\
\text { RCABG }\end{array}$ & 30 & $\begin{array}{c}65.8 \pm \\
10.4\end{array}$ & 23 & 17 & 9 & 7 & NS & NS & $\begin{array}{c}68.00 \pm \\
11.08\end{array}$ & NS & NS \\
\hline
\end{tabular}

$<<$ Confirm our editing of this head to: Age, $y \pm S D>>$

$<<$ Add a footnote with a definition of NS.>>

<<For the columns with "n (\%)": (1) why do some items have the percent sign and others do not? (2) why do some of the data not have percent listed?>> <<Should the COPD column have " $\mathrm{n}(\%)$ " in its head? Also, why do some of the data not have percent listed? >>

<<Should the LVEF, EuroSCORE, and BMI columns have unit information in the heads? Also, the range and perhaps SD may need to be indicated. A footnote might be best for these.>

between HCR and MICR have a significant difference (OR 0.72; 95\% CI, 0.26-2.00; $P=.53$ ). In subgroup analysis, HCRs are similar with MICRs (OR $0.51 ; 95 \%$ CI, $0.11-2.25 ; Z=0.89 ; P=.37)$ and RCABGs $(\mathrm{OR} 1.07 ; 95 \%$ CI, $0.52-2.20 ; Z=0.17 ; P=.86)$. MI (OR 0.62; $95 \% \mathrm{CI}$,
0.18-2.22; $\mathrm{Z}=0.73 ; \mathrm{P}=.47$ ), shock (OR $1.02 ; 95 \% \mathrm{CI}$, $0.35-2.94 ; P=.98)$, renal failure (OR $0.57 ; 95 \% \mathrm{CI}, 0.23$ $1.40 ; P=.22$ ), long-term follow-up survival (OR 0.70; $95 \%$ CI, $0.35-1.40 ; P=.31$ ) had no difference between HCRs and MICRs. 
Table 4. Results of Metaanalysis of Clinical Outcome

\begin{tabular}{|c|c|c|c|c|c|c|c|c|}
\hline In-hospital mortality & 4 & $959 / 1954$ & 34 & Random & $\mathrm{M}-\mathrm{H}$ & 0.91 & $0.22-3.77$ & .9 \\
\hline Shock & 4 & $959 / 1954$ & 0 & Random & $\mathrm{M}-\mathrm{H}$ & 1.02 & $0.35-2.94$ & .98 \\
\hline MACCE & 4 & $819 / 1954$ & 33 & Random & $\mathrm{M}-\mathrm{H}$ & 0.72 & $0.26-2.00$ & .53 \\
\hline Mortality in the long term & 3 & $613 / 595$ & 70 & Random & $\mathrm{M}-\mathrm{H}$ & 0.7 & $0.35-1.40$ & .31 \\
\hline Second Clinical Outcome & No. & $\mathrm{HCR} / \mathrm{MICR}$ & $12(\%)$ & Analysis Model & Statistics Method & OR/WMD & $95 \% \mathrm{Cl}$ & $\mathrm{P}$ \\
\hline Reoperation & 5 & $1066 / 2366$ & 77 & Random & $\mathrm{M}-\mathrm{H}$ & 1.06 & $0.41-2.72$ & .9 \\
\hline Blood transfusion & 4 & $579 / 1138$ & 17 & Random & $\mathrm{M}-\mathrm{H}$ & 0.43 & $0.31-0.59$ & .00001 \\
\hline ICU LOS & 3 & $166 / 198$ & 30 & Random & $\mathrm{M}-\mathrm{H}$ & -11.46 & -18.76 to -4.25 & .02 \\
\hline Operation time & 3 & $352 / 232$ & 92 & Random & $\mathrm{M}-\mathrm{H}$ & -33.55 & $-72.87 \sim 5.78$ & .09 \\
\hline Hospital stay & 5 & $1351 / 565$ & 97 & Random & $\mathrm{M}-\mathrm{H}$ & -1.34 & -2.42 to 0.26 & .01 \\
\hline Ventilator time & 4 & $392 / 262$ & 89 & Random & $\mathrm{M}-\mathrm{H}$ & -2.66 & -4.95 to -0.38 & .02 \\
\hline Chest drainage & 2 & $140 / 170$ & 94 & Random & $\mathrm{M}-\mathrm{H}$ & -170.78 & $\begin{array}{c}-612.17 \text { to } \\
270.62\end{array}$ & .45 \\
\hline Cost & 2 & $233 / 235$ & 22 & Random & $\mathrm{M}-\mathrm{H}$ & 0.01 & -0.25 to 0.27 & .92 \\
\hline
\end{tabular}

*M-H, Mantel-Haenszel. <<Confirm this footnote added. >>

$<<$ What is RF? Radiofrequency? Rheumatoid factor? >>

Second clinical end points. Five studies reported on reoperation. Three studies reported on infection. HCR was associated with less ICU LOS (WMD -11.46 hours; 95\% CI, -18.76 to $-4.25 ; P=.02$ ), hospital time (WMD -1.34 hours; $95 \% \mathrm{CI},-2.42$ to $-0.26 ; P=.01$ ), blood transfusion (OR $0.43 ; 95 \%$ CI, 0.31 to $0.59 ; P<.00001$ ), ventilator time (WMD $-2.66 \mathrm{~d}$; $95 \% \mathrm{CI}-4.95$ to $0.38 ; P=.02$ ). However, there was no significant difference in terms of bleeding (OR 1.14 ; $95 \% \mathrm{CI}, 0.08$ to $0.97 ; P=.85$ ).

\section{Bias Assessment}

A funnel plot with a proximal standard error between HCR and MICR is shown in Figure 6 and indicates no significant statistical bias.

\section{DISCUSSION}

In this metaanalysis, HCR was noninferior to MICR in terms of in-hospital mortality, MACCE, shock, MI, long-term survival, total variable cost, and some surgical complications (including renal failure, chest drainage, bleeding), whereas HCR was associated with a reduced need for reoperation,
ICU LOS, hospital time, ventilator time, and blood transfusion in comparison with MICR and had less infection than MICR. Our study was the first metaanalysis on clinical outcomes of HCR compared with MICR, and our findings suggests HCR is a safe and durable alternative to MICR.

The common advantages of HCR and MICR compared with traditional CABG are the avoidance of cardiopulmonary bypass, aortic clamping, and complete sternotomy when one uses minimally invasive surgical techniques. The difference between HCR and MICR is the durability and survival advantage of LIMA-LAD and PCI for non-LAD in HCR for patients with multivessel CAD, but for patients with MICR, non-LAD has been treated by MIDCAB or RCABG, whereas LIMA-LAD is the same with HCR. Our studies found that inhospital mortality, MACCE, shock, MI, long-term survival, and total variable cost have no significant difference between HCR and MICR. It means that PCI for non-LAD offer similar major clinical outcomes compared with MIDCAB/ RCABG for non-LAD in the complexity of the coronary lesion. With using newer generation stents, the clinical outcome has improved after PCI in HCR, and the early restenosis rate of non-LAD vessels after PCI with drug-eluting stent seems to be significantly less than saphenous vein graft. 


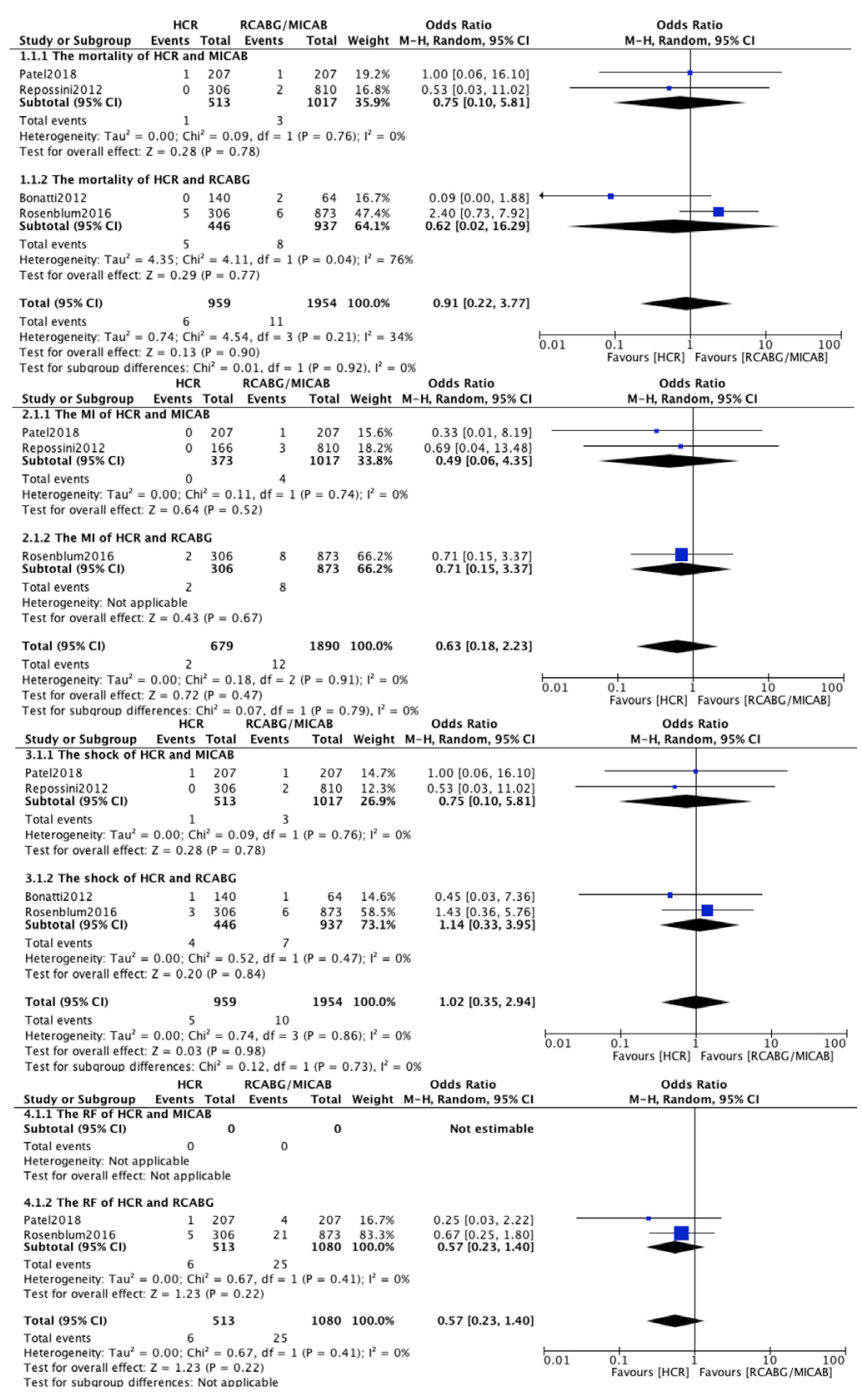

Figure 2. Clinical outcome of metaanalysis between HCR and MICR. $\mathrm{M}-\mathrm{H}$, Mantel-Haenszel; Favours, favors,

Mohr and associated reported LITA to LAD with MIDCAB and PCI to non-LAD had better clinical outcome than others with surgery choice [Mohr 2013]. However, with the development of surgery technique in MICR, especially with bilateral internal mammary artery grafts (BITA) and others arteries bridge (for example radial artery, gastro-epiploic artery), performed minimally invasively, new stabilizers, and videoassisted thoracoscopic surgery, the MICR evolved as a new surgical stagey that was not only minimally invasive but also improved the survival rate and long-term patency and had fewer surgery complications compared with the HCR.

The cost of HCR were combines costly less invasive hardware and surgical disposables, catheter-based coronary intervention and very expensive coronary implants device. However, these costs may be share out by long hospital stay costs and improved surgery complications cost compared with conventional CABG. But for MICR, the lower surgery complications may lead to a decrease in total cost similar to HCR [Wu 2017].

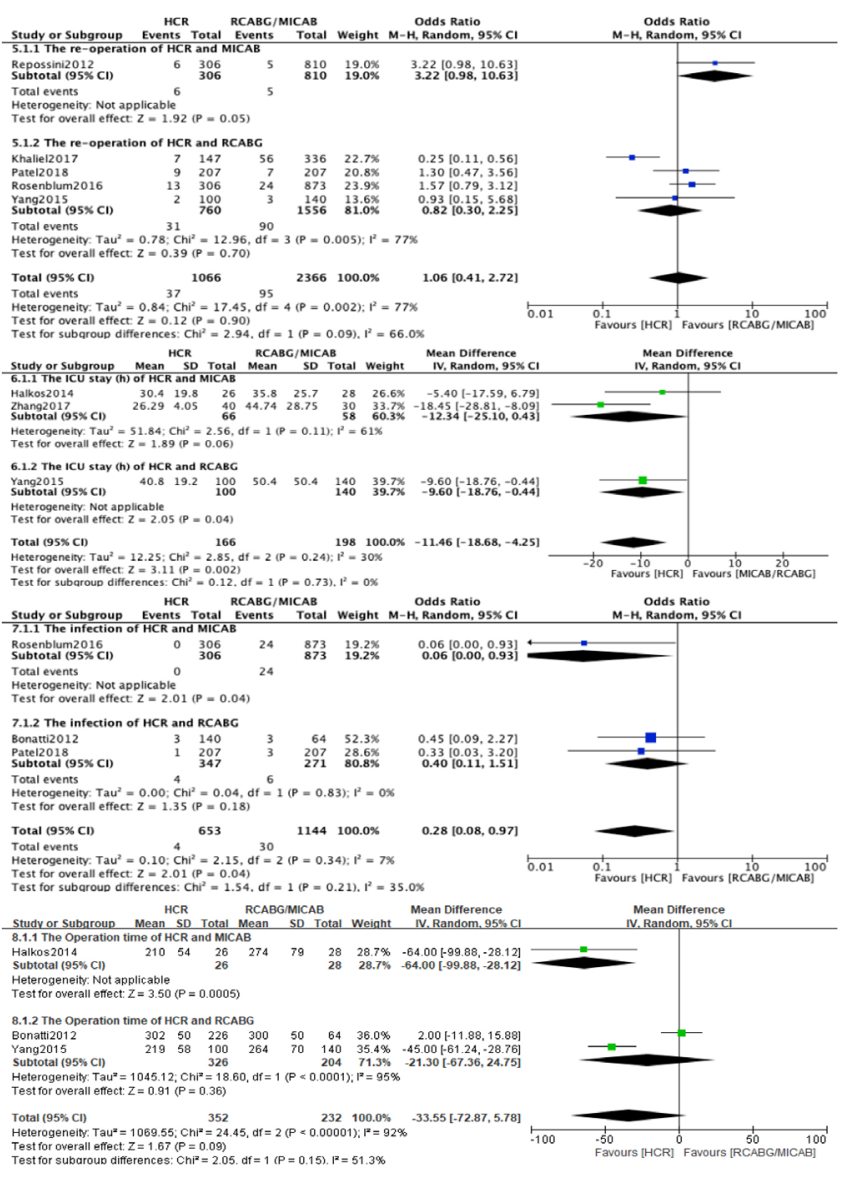

Figure 3. Clinical outcome of metaanalysis between HCR and MICR. M-H, Mantel-Haenszel; IV, inverse variance; Favours, favors,

In this analysis, the significantly low requirement of blood transfusion in HCR was attributed to the short time of MIDCAB compared with MICR despite the use of aspirin and clopidogrel [Nenna 2016]. The ICU LOS, hospital time, and ventilator time were significantly shorter in HCR mean that HCR had a quick recovery which were contributed to lower blood transfusion and reduced systemic inflammation with improved postoperative recovery. And what is more, the better myocardial protection and advances in the catheter interventions are also other mechanisms for quickly recovery. Some factors influenced the quick recovery, including the surgeon's experience, learning-curve effect, cooperation of physician and surgeon, and postoperative management [Hart 1999]. The RCABG was blunted compared with the conventional CABG due to the inflammatory response, for example, the cytokine and C-reactive protein release [Stastny 2018]. A similar clinical outcome [Misumida 2018] showed no significant difference between conventional CABG and RCABG and fewer blood products, shorter ICU stay, hospital stay, and less pain compared with conventional CABG [Messerli 2018].

Despite the potential benefits of MICR, the technique has not been perfected. This can be attributed to a number of 


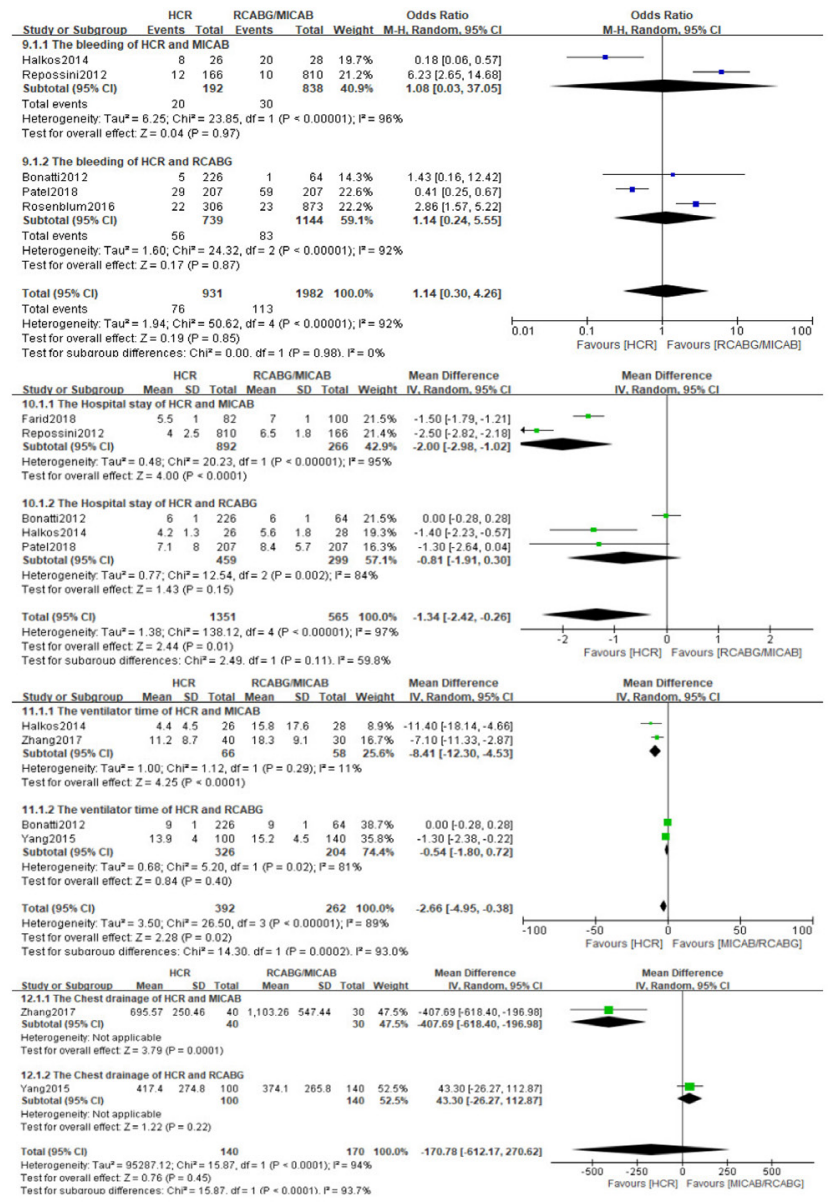

Figure 4. Clinical outcome of metaanalysis between HCR and MICR. $\mathrm{M}-\mathrm{H}$, Mantel-Haenszel; IV, inverse variance; Favours, favors,

factors, including long-learning curing and operation time with increased difficulty surgery, the difficulties for older patients with serval left dysfunction, the use of vascular bridge which were suitable operation and better long-term patency. The surgical expose of MICR for multivessel disease is made more laterally which lead to rib injury and costochondral .what's more, hand-sewn proximal and distal anastomose. In general, the ideal candidate for HCR has LAD to LIMA and proximal lesions in the right coronary artery and circumflex branch (LCX) with PCI. But for MICR, the lesions in the right coronary artery and LCX may increasing the difficulty though left thoracic approach [Saran 2018] and a 92\% overall graft patency and $100 \%$ LIMA patency at 6 months [Ruel 2014]. Therefore, the suitable patients for MICR should be performed on stable patients with preserved ventricular function and with no severe chest deformities or pulmonary comorbidities.

\section{Limitations}

This study has several limitations that should be acknowledged. First, the main drawback of our metaanalysis was the retrospective nature of the available data. The

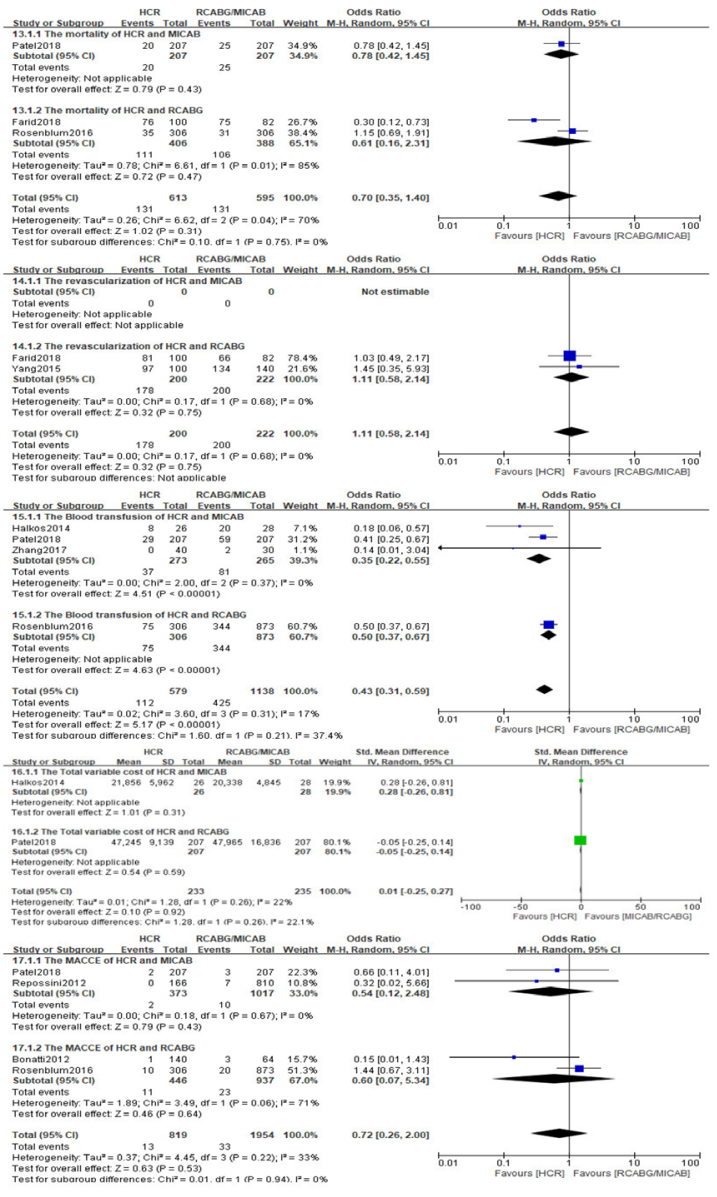

Figure 5. Clinical outcome of metaanalysis between HCR and MICR. M-H, Mantel-Haenszel; IV, inverse variance; Favours, favors,

limited observational studies subject to section bias and we only included studies with similar baseline characteristic in order to limit this bias. Second, the results of the included studies are from MIDCAB/RCABG compared with HCR. But the subgroup analysis has obvious heterogeneity and a small sample size, which reduces the statistical power. The multi-institutional RCT trials were require in order to further validation and comprehensive evaluation index also need to require. Finally, the different definitions of major clinical outcome and secondary clinical outcome varied to some degree, which also have weakened the evidence in our analysis.

\section{CONCLUSION}

This metaanalysis found that HCR was noninferior to MICR in terms of in-hospital mortality, MACCE, shock, MI, long-term survival, total variable cost, and surgical complications (including renal failure, chest drainage, bleeding), whereas HCR was associated with a reduced need for ICU LOS, hospital time, and blood transfusion in comparison to MICR and had less infection than MICR. This warrants 


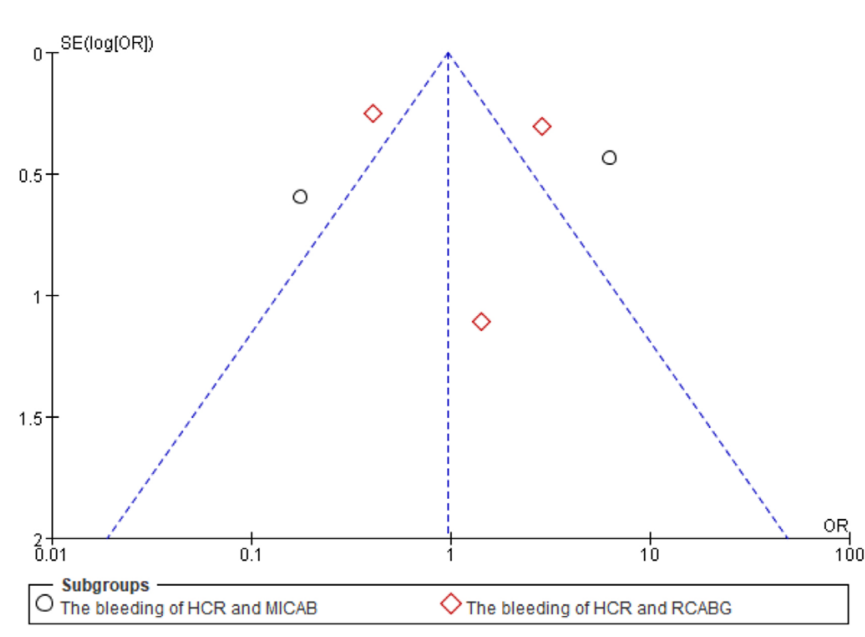

Figure 6. A funnel plot of bleed between HCR and MICR.

further validation in multicentric RCT trials to definitively assess the benefits and risks in these 2 surgery techniques.

\section{ACKNOWLEDGMENTS}

This work was partly supported by the National Natural Science Foundation of China (grant no. 11902149). This work is also sponsored by China Postdoctoral Science Foundation Grant (grant no. 2018M640030).

\section{REFERENCES}

Aziz O, Rao C, Panesar SS, et al. 2007. Meta-analysis of minimally invasive internal thoracic artery bypass versus percutaneous revascularisation for isolated lesions of the left anterior descending artery. BMJ 334(7594):617.

Barsoum EA, Azab B, Shah N, et al. 2015. Long-term mortality in minimally invasive compared with sternotomy coronary artery bypass surgery in the geriatric population (75 years and older patients). Eur J Cardiothorac Surg 47(5):862-7.

Bonatti JO, Zimrin D, Lehr EJ, et al. 2012. Hybrid coronary revascularization using robotic totally endoscopic surgery: perioperative outcomes and 5-year results. Ann Thorac Surg 94(6):1920-6; discussion 1926.

Farid S, Ali JM, Stohlner V, et al. 2018. Long-term outcome of patients undergoing minimally invasive direct coronary artery bypass surgery: a single-center experience. Innovations (Phila) 13(1):23-8.

Halkos ME, Ford L, Peterson D, et al. 2014. The impact of hybrid coronary revascularization on hospital costs and reimbursements. Ann Thorac Surg 97(5):1610-5; discussion 1615-6.

Harskamp RE, Bagai A, Halkos ME, et al. 2014. Clinical outcomes after hybrid coronary revascularization versus coronary artery bypass surgery: a meta-analysis of 1,190 patients. Am Heart J 167(4):585-92.

Hart JC, Spooner T, Edgerton J, Milsteen SA. 1999. Off-pump multivessel coronary artery bypass utilizing the Octopus tissue stabilization system: initial experience in 374 patients from three separate centers.
Heart Surg Forum 2(1):15-28.

Khaliel F, Giambruno V, Chu MW, Sridhar K, Teefy P, Kiaii BB. 2017. Consequences of hybrid procedure addition to robotic-assisted direct coronary artery bypass. Innovations (Phila) 12(3):192-6.

Kolessov VI. 1967. Mammary artery-coronary artery anastomosis as method of treatment for angina pectoris. J Thorac Cardiovasc Surg 54(4):535-44.

Messerli AW, Misumida N. 2018. Hybrid coronary revascularization 5 years on : is clinical equipoise good enough? JACC Cardiovasc Interv 11(9):853-5.

Misumida N, Moliterno DJ. 2018. Hybrid coronary revascularization: time for a new comparator? Catheter Cardiovasc Interv 91(2):213-4.

Mohr FW, Morice MC, Kappetein AP, et al. 2013. Coronary artery bypass graft surgery versus percutaneous coronary intervention in patients with three-vessel disease and left main coronary disease: 5-year follow-up of the randomised, clinical SYNTAX trial. Lancet 381(9867):629-38.

Nenna A, Spadaccio C, Lusini M, Barbato R, Chello M, Nappi F. 2016. Hybrid coronary revascularization: an attractive alternative between actual results and future trends. Surg Technol Int 28:204-10.

Phan K, Wong S, Wang N, Phan S, Yan TD. 2015. Hybrid coronary revascularization versus coronary artery bypass surgery: systematic review and meta-analysis. Int J Cardiol 179:484-8.

Puskas JD, Halkos ME, DeRose JJ, et al. 2016. Hybrid coronary revascularization for the treatment of multivessel coronary artery disease: a multicenter observational study. J Am Coll Cardiol 68(4):356-65.

Repossini A, Tespili M, Saino A, et al. 2013. Hybrid revascularization in multivessel coronary artery disease. Eur J Cardiothorac Surg 44(2):28893; discussion 293-4.

Rosenblum JM, Harskamp RE, Hoedemaker N, et al. 2016. Hybrid coronary revascularization versus coronary artery bypass surgery with bilateral or single internal mammary artery grafts. J Thorac Cardiovasc Surg 151(4):1081-9.

Ruel M, Shariff MA, Lapierre H, et al. 2014. Results of the minimally invasive coronary artery bypass grafting angiographic patency study. J Thorac Cardiovasc Surg 147(1):203-8; discussion 208-9.

Ruel M, Une D, Bonatti J, McGinn JT. 2013. Minimally invasive coronary artery bypass grafting: is it time for the robot? Curr Opin Cardiol 28(6):639-45.

Saran N, Locker C, Said SM, et al. 2018. Current trends in bilateral internal thoracic artery use for coronary revascularization: extending benefit to high-risk patients. J Thorac Cardiovasc Surg 155(6):2331-43.

Sim EK, Goh JJ, Cheng A, Tan HC, Lim YT. 1999. Minimally invasive direct coronary artery bypass. Singapore Med J 40(2):75-7.

Soylu E, Harling L, Ashrafian H, et al. 2016. A systematic review of the safety and efficacy of distal coronary artery anastomotic devices in MIDCAB and TECAB surgery. Perfusion 31(7):537-43.

Stastny L, Kofler M, Dumfarth J, et al. 2018. Long-term clinical and computed tomography angiographic follow-up after totally endoscopic coronary artery bypass grafting. Innovations (Phila) 13(1):5-10.

Thiele H, Neumann-Schniedewind P, Jacobs S, et al. 2009. Randomized comparison of minimally invasive direct coronary artery bypass surgery versus sirolimus-eluting stenting in isolated proximal left anterior descending coronary artery stenosis. J Am Coll Cardiol 53(25):2324-2331.

Wu S, Ling Y, Fu Y, et al. 2017. Mid-term follow-up outcomes of 2-staged hybrid coronary revascularization compared with off-pump 
coronary artery bypass for patients with multivessel coronary artery disease. Wideochir Inne Tech Maloinwazyjne 12(2):178-85.

Yang M, Wu Y, Wang G, Xiao C, Zhang H, Gao C. 2015. Robotic total arterial off-pump coronary artery bypass grafting: seven-year singlecenter experience and long-term follow-up of graft patency. Ann Thorac
Surg 100(4):1367-73.

Zhang LF, Ling YP, Yang H, Gong YC, Song ZM, Wan F. 2017. [Comparison of outcomes of two minimally invasive approaches for multivessel coronary revascularization]. Beijing Da Xue Xue Bao Yi Xue Ban, 49(6):1066-70. Chinese. 